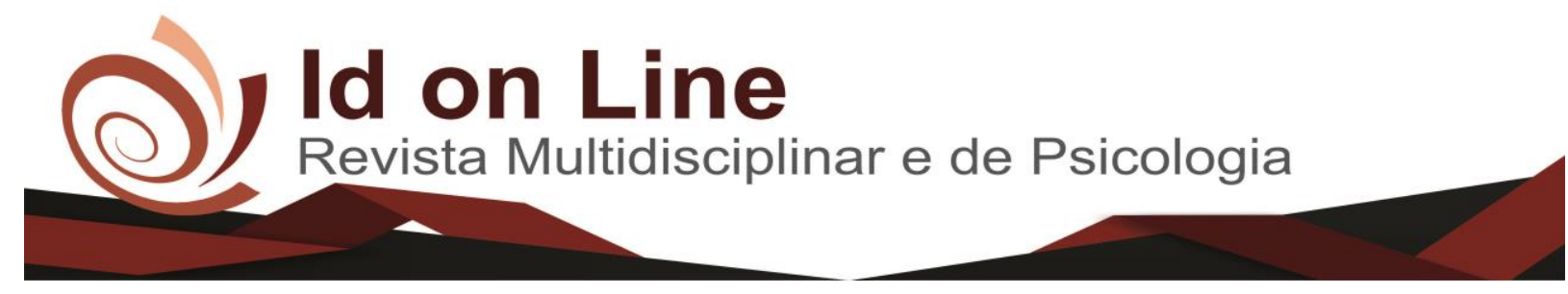

Artigo

\title{
Fatores Motivacionais que influenciam no desempenho dos colaboradores no Ambiente de Trabalho
}

\author{
Cimara de Souza Martins ${ }^{1}$; Mariana Emídio Oliveira Ribeiro ${ }^{2}$; Bianca Inez Antoniolli ${ }^{3}$; José Marcos Santos da Silva ${ }^{4}$
}

\begin{abstract}
Resumo: O ser humano é capaz de exercer diversas funções com maior ou menor eficiência, essa aptidão diferi de uma pessoa para outra. No entanto, para que o máximo de eficiência seja obtida nas organizações empresariais, é necessário que estejam bem motivados. Portanto, este estudo teve como objetivo verificar se a motivação é um fator relevante no desempenho dos colaboradores da empresa, bem como evidenciar os fatores motivacionais no ambiente de trabalho e identificar se o ambiente de trabalho interfere no desempenho do colaborador. A metodologia utilizada foi através do método de indução e pelo procedimento monográfico no qual foi aplicado questionários com questões fechadas e abertas e pesquisa bibliográfica para embasar os dados. Ao final do estudo percebeu-se que os indivíduos são distintos no que se referem aos fatores motivacionais, onde as necessidades são diferenciadas entre si, gerando diversos padrões de comportamento, valores sociais e a capacidade para atingir os objetivos, tornando-se mais complexo por variarem no mesmo indivíduo conforme o tempo. Este trabalho vem colaborar para que as empresas invistam em seus funcionários, através de cursos ou gratificações, que os valorizem pela sua contribuição e assim cresçam juntos, haja visto que, o contrário dessas atitudes, têm consequências como a depreciação da empresa.
\end{abstract}

Palavras-chave: Colaboradores. Motivação. Desempenho.

\section{Motivational Factors that Influence Employees' Performance in the Work Environment}

\begin{abstract}
The human being is able to perform several functions with greater or lesser efficiency, this notification may be delayed fitness from one person to another. However, for maximum efficiency is achieved in business organizations, it is necessary to be well motivated. Therefore, the objective of this study was to verify whether the motivation is an important factor in the performance of the company's employees, as well as highlight the motivational factors in the work environment and identify if the work environment interferes with the performance of the employee. The methodology used was through the method of induction and the monographic procedure in which it has been applied questionnaires with open and closed questions and bibliographical research to back up the data. At the end of the study realized that individuals are distinct in that relate to the motivational factors, where the needs are differentiated among themselves, generating several patterns of behavior, social values and the ability to achieve the goals, becoming more complex by the same individual vary according to the time. This work has been collaborating for companies to invest in their employees, through courses or gratuities, that the value for their contribution and thus grow together, there is seen as the opposite of these attitudes have consequences such as the depreciation of the company.
\end{abstract}

Key-words: Collaborators. Motivation. Performance.

${ }^{1}$ Discente no Curso de Administração da Faculdade de Alta Floresta (FAF).

2 Docente no curso de Administração, Ciências Contábeis e Gestão em Agronegócio. Mestranda no PPGAD em Ambiente e Desenvolvimento da UNIVATES. Pós Graduada em Planejamento, Implantação e Gestão em EaD na Claretiano, Pós Graduação em Didática de Ensino Superior na FAF, Pós Graduada em Gestão Estratégica de Pessoas na Unopar - Sede Londrina/Pr Presencial. Graduada em Administração.

${ }^{3}$ Curso de Administração da Faculdade de Alta Floresta (FAF).

${ }^{4}$ Graduação em Administração de Empresas pela Escola de Administração de Empresas da Bahia - UNIFACS. Especialização em Administração Hospitalar pela UFMT, Contabilidade Auditoria e Perícia pela AJES, Especialização em Didática do Ensino Superior pela UNIFLOR - União das Faculdades de Alta Floresta.

262 Id on Line Rev. Mult. Psic. V.11, N. 39. 2017 - ISSN 1981-1179

Edição eletrônica em http://idonline.emnuvens.com.br/id 


\section{Introdução}

A globalização e a concorrência no âmbito empresarial, associadas aos custos de contratação e formação profissional, faz-se intensas as buscas pelos melhores funcionários. Mas, para que isso ocorra os envolvidos no processo devem estar motivados e dispostos a alcançar metas e objetivos propostos pelas empresas.

O diferencial competitivo das instituições não está associado à tecnologia empregada ou à eficácia de produção, mas aos indivíduos que trabalham, tornando a motivação um assunto de suma importância.

No que diz respeito à motivação, não há um preceito geral, que possa ser aplicado a todos. É necessária uma reflexão para se chegar a um consenso do que é importante para cada funcionário. Mas há algo que costuma ser comum a um grande número de trabalhadores, a forma como se vê o trabalho. Quem define o trabalho como uma obrigação penosa, certamente tem dificuldades de se sentir motivado, ao contrário das que gostam do que fazem, pois conseguem tolerar circunstâncias de estresse por longos períodos e se adaptam mais fácil em qualquer situação.

O tema em questão é relevante para as empresas, considerando-se que o ser humano é dotado de características únicas e complexas e o seu comportamento tanto no trabalho, quanto em outro ambiente, muitas vezes é influenciado pelos fatores considerados motivacionais. Assim, o funcionário que trabalha motivado e satisfeito produz mais, falta menos ao emprego e traz maiores benefícios para a organização.

Dentro do exposto, levantou-se o seguinte questionamento: a motivação influencia no desempenho dos funcionários no ambiente de trabalho? Para tanto, partiu-se das hipóteses de que a falta de motivação pode interferir no bom desempenho dos colaboradores dentro da empresa; existe uma relação agradável entre colaborador e superior; o salário é o fator que motiva os colaboradores no desempenho de seu trabalho e o ambiente de trabalho interfere no desempenho da equipe.

Os objetivos que nortearam a pesquisa foram: verificar se a motivação é um fator relevante no desempenho dos colaboradores da empresa;

a) evidenciar os fatores motivacionais no ambiente de trabalho:

b) identificar se o ambiente de trabalho interfere no desempenho do colaborador.

Esse estudo justifica-se pelo competitivo mercado de trabalho no qual há 
necessidade de pessoas capacitadas e motivadas a fazer um bom trabalho. E para que isso ocorra à empresa precisa adotar uma política motivadora, podendo garantir o melhor desempenho e a permanência do quadro de funcionários.

\section{Embasamento Teórico}

De acordo com Bergamini (1997), antes da Revolução Industrial, a maneira predominante para motivar os colaboradores incidia na aplicação de punições, instituindo, dessa forma, uma atmosfera de medo. Tais punições não eram somente de caráter psicológico, podendo surgir através de restrições financeiras, como descontos na remuneração, chegando a prejuízos de ordem física. Este pensamento aos poucos foi sendo substituído pela Escola de Administração Científica que, desde os seus primórdios, estudava aspectos motivacionais, uma vez que a tarefa do trabalhador era a sua preocupação. Em 1900, Taylor, fundamentandose em fatores econômicos, começou a discussão sobre motivação, assumindo que o dinheiro era o maior motivador.

Bergamini (1997, p. 21) aduz que "os incentivos econômicos vão se tornando direitos, em vez de recompensas", ou seja, a remuneração e os incentivos transformam em direito do colaborador. Assim, no final da década de 1920, surge uma filosofia denominada Escola de Relações Humanas.

Para Chiavenato (2003), a Teoria das Relações Humanas foi basicamente um movimento de oposição à Teoria Científica e a Teoria Clássica da Administração. Foi uma grande revolução conceitual, ou seja, tirou-se a ênfase das tarefas e da estrutura organizacional, para dar ênfase às pessoas que trabalham ou participam das organizações.

As Teorias Motivacionais manifestaram-se após a Escola de Relações Humanas alertarem sobre os trabalhadores que não possuem motivação e por isso possuem pequeno desempenho nas atividades da empresa. Têm como principais pensadores são Abraham Maslow, Douglas McGregor e Frederick Herzberg cujo objetivo era de aplicar o índice de motivação das pessoas, baseado em suas necessidades e aspirações.

Abraham Maslow desenvolveu em 1943 a Teoria de Maslow denominada também como Pirâmide de Maslow ou Hierarquia das Necessidades. O objetivo dessa teoria é de determinar uma equivalência de valores para as necessidades humanas, classificando-as 
de acordo com grupos associados com a natureza ou prioridade.

Conforme Chiavenato (2003), a classificação das necessidades de Maslow possui cinco grupos:

a) Fisiológico: agrupa necessidades agregadas à falta de alimentação, água, descanso, vitalidade, entre outras associadas à sobrevivência do ser humano;

b) Segurança: direcionada a qualquer perigo real ou imaginário de óbito que fazem o trabalhador querer proteção. E também esta atrelada a sobrevivência.

c) Social: se refere à relação entre pessoas. A partir do momento que o sujeito alcançou os atributos fisiológicos e de segurança, ele busca relacionar-se com os demais com a finalidade de consolidá-los.

d) Estima: possui relação com o ego de forma que ao conseguir atender as necessidades sociais o orgulho e a autoestima são o foco para diferenciá-lo dos outros.

e) Realização: corresponde a busca do ser humano em alcançar seu melhor.

No ambiente de trabalho, Chiavenato (2003) expõe que, as necessidades dizem respeito à remuneração básica e requisitos mínimos de trabalho, o segurança com benefícios, a grupos, colegas, supervisores e clientes, ao reconhecimento e ao aumento de atribuições e às oportunidades de treinamento e de ampliação da criatividade para a ascensão do progresso pessoal.

A Teoria dos Dois Fatores desenvolvida por Herzberg (1998) dispõe que a satisfação no trabalho, é consequência de como o colaborador se sente neste ambiente e dos fatores que influenciam em sua motivação e desmotivação. Em sua teoria, dois fatores são fundamentais para a satisfação: higiênicos e motivacionais.

Os higiênicos referem-se aos pontos externos dos indivíduos, ou seja, o indivíduo enquanto trabalha está cercado de condições físicas, que são: salário, política da empresa, benefícios sociais e regulamentos internos etc.

As empresas utilizam esses fatores higiênicos para evitar a insatisfação dos indivíduos, mas por não serem de efeitos duradouros deixam de ter tanta importância com o tempo.

Já os fatores motivacionais referem-se segundo Herzberg (1998), aos sentimentos de concretização de crescimento e reconhecimento profissional, distintos dos higiênicos, os motivacionais são duradouros, são exprimidos por meio dos exercícios das tarefas e 
atividades que fornecem desafios suficientes e significativos ao trabalho.

Para Herzberg (1998), os desafios nas atividades instigam os indivíduos a aumentarem a produtividade em um nível de perfeição, ou seja, os desafios fazem com que as pessoas sintam que elas e as atividades desempenhadas pelas mesmas são importantes para sua realização e para o desenvolvimento da organização.

Assim, a insatisfação no cargo é função do ambiente e da supervisão, isso é chamando de fator higiênico, a satisfação no cargo é função das atividades desafiadoras e estimulantes do cargo que é chamada de fator motivacional.

A Teoria $\mathrm{X}$ (sobre os trabalhadores) e a Teoria $\mathrm{Y}$ (sobre as organizações) formuladas por McGregor (1976) comparam dois estilos opostos de administrar. A primeira parte-se do pressuposto de que o homem é, por natureza, indolente evita o trabalho não tem ambição, desgosta da responsabilidade e prefere ser dirigido. A teoria assume que o indivíduo é centrado, indiferente às necessidades organizacionais, resistente a mudanças, ingênuo e nada brilhante.

A Teoria Y encerra a suposição de que o indivíduo não é, por natureza, desanimado e não confiável. Essa teoria propõe que as pessoas podem se autodirigir e ser criativas no trabalho, desde que sejam motivadas. Dentro dessas considerações, o administrador tem como tarefa essencial expandir esse potencial nos indivíduos.

Assim, percebe-se que na Teoria X o indivíduo é motivado pelo menor esforço, necessitando de um acompanhamento por parte do gestor. Já na Teoria Y, as pessoas são motivadas pelo máximo esforço, demandando uma participação maior nas decisões e negociações inerentes ao seu trabalho.

Portanto, a motivação é o conjunto de forças internas e externas que fazem que os funcionários adotem certos comportamentos. Idealmente, esses comportamentos são orientados para a consecução de uma meta organizacional. Para Soto (2005, p. 66):

\footnotetext{
Motivação é a pressão interna surgida de uma necessidade, também interna, que excitando (via eletroquímica) as estruturas nervosas, origina um estado energizado que impulsiona o organismo a atividade iniciando, guiando e mantendo a conduta até que alguma meta (objetivo, incentivo) seja conseguida ou a resposta seja bloqueada.
}

A motivação exige a descoberta e o entendimento das necessidades e desejos dos funcionários, uma vez que ela se origina no interior de um indivíduo. Gil (2008, p. 202) 
acredita que motivação é "[...] a força que estimula as pessoas a agir".

Estudar a motivação humana permite compreender e conhecer um pouco mais sobre o comportamento do indivíduo. Dessa forma, é possível prever e, de certa maneira, controlar pessoas, atuando por meio do monitoramento das necessidades ou dos motivos que impulsionam o comportamento e dos objetivos e metas que o originaram.

Para Bergamini (1997), à motivação possui uma sequencia de fatores que causam a satisfação e suas principais características estão ligadas ao trabalho, como a realização, reconhecimento, responsabilidade e possibilidades de crescimento na empresa.

A motivação relaciona-se intimamente com a personalidade do ser humano e com seu desenvolvimento mental, emocional, profissional e social.

Para Chiavenato (1999), a motivação é baseada nas necessidades de crescimento e seus benefícios aparecem em um longo período de trabalho já que a recompensa final da motivação é o crescimento pessoal. O ser humano é motivado pela necessidade de 'estar junto', 'ser reconhecido', de receber atenção.

De acordo com Kannane (1995), as atitudes correspondem a um ciclo motivacional onde a procura do equilíbrio é essencial, mas nem sempre obtida.

A motivação se origina quando há uma necessidade, ou seja, o indivíduo sai da sua zona de conforto, onde havia um equilíbrio e agora se estabelece a insatisfação.

Segundo Chiavenato (2002, p. 81):

Esse estado leva o indivíduo a um comportamento ou ação, capaz de descarregar a tensão ou de livrá-lo do desconforto e do desequilíbrio. Se o comportamento for eficaz, o indivíduo encontrará a satisfação da necessidade e, portanto, a descarga de tensão provocada por ela.

Quando essa necessidade é satisfeita, há o retorno do equilíbrio e adaptação ao meio novamente. Dessa forma, o ciclo motivacional começa com uma incitação para o desempenho criando um desequilíbrio. Enquanto essa necessidade não for satisfeita, o conflito não minimiza e o desequilíbrio se mantém. Um novo estado de equilíbrio só será alcançado quando o indivíduo conseguir, praticar os procedimentos apropriados à satisfação dessa necessidade. 
A satisfação da necessidade está inteiramente proporcional ao estado de equilíbrio, entretanto quando este ciclo não se completa, o conflito pode ser resolvido a partir de três modos distintos de acordo com Bergamini (1997, p. 87):

Satisfação da necessidade: Ocorre quando o ciclo se fecha (mesmo a cabo de algum tempo) plenamente. Frustração da necessidade: A partir do estado de tensão no organismo, o ciclo é bloqueado impedindo a satisfação e provocando a frustração. Compensação da necessidade: Quando o ciclo é bloqueado, o impedimento da satisfação é compensado por um desvio em contato para aliviar a tensão.

Para Vianna (1999), o indivíduo pode chegar a um nível de frustração (por não ter alcançado o objetivo satisfazendo sua necessidade) ou então o efeito produzido pode resultar em um comportamento compensatório, isto é, a redução da tensão verifica-se por uma compensação que substitua a satisfação (não verificada) daquela necessidade.

Deve ainda ter presente que os estados de equilíbrio segundo Chiavenato (2003) são sempre passageiros, visto que, satisfeita a necessidade, outra surge provocando um novo estado de tensão e desequilíbrio que se conserva até sua satisfação.

Percebe-se que os indivíduos são distintos no que se refere às ações motivacionais, e que as necessidades variam de pessoa para pessoa, gerando diversos padrões de comportamento; os valores sociais também são distintos e a capacidade para atingir os objetivos são igualmente diferentes. O que ainda torna-se mais complexo, já que as necessidades, os valores sociais e as capacidades variam no mesmo indivíduo conforme o tempo.

Portanto, funcionários motivados provavelmente são mais produtivos. Segundo Robbins (2010), alguns pesquisadores acreditavam que a relação motivação no trabalho e desempenho era um mito.

Porém, uma revisão de mais 300 estudos sugeriu que a correlação é realmente forte. ParaRobbins (2010, p. 74):

À medida que mudamos do nível individual para o organizacional, também encontramos bases para suportara relação motivação-desempenho. Quando dados de satisfação e produtividade são coletados para a organização como um todo, vemos que organizações com um número maior de funcionários motivados tendem a ser mais eficientes que aquelas com um número menor deles. 
De acordo com a revista Exame, verificou-se que os resultados das empresas consideradas melhores para se trabalhar foram superiores aos das 'melhores e maiores' empresas que, por si só, já obtêm resultados significativos. Essa observação sugere que as empresas onde prevalece à motivação com o trabalho tendem a obter melhor desempenho.

Fiorelli (2004) verificou que, quanto maior a motivaçãodos funcionários, tendo em conta fatores como a capacitação, o tempo de locomoção até ao trabalho e os materiais utilizados, menor será sua rotatividade na empresa.

A desmotivação no trabalho e as relações antagônicas com os colegas são causadoras de muitos comportamentos que as organizações consideram indesejáveis, incluindo tentativas de sindicalização, uso de álcool, furtos e impontualidade.

Segundo Robbins (2010), pesquisadores defendem que esses comportamentos são indicadores de uma síndrome maior que se chamariadesvio de comportamento no ambiente de trabalho (ou afastamento do empregado). Se os empregados não gostam de seu ambiente de trabalho, de alguma maneira eles vão reagir, embora não seja sempre fácil saber como. Um empregado pode pedir demissão. Outro podeutilizar o horário de trabalho para navegar na Internet ou levar para casa materiais de trabalho para uso pessoal. Enfim, os trabalhadores que não gostam de seu trabalho se vingam' de várias formas e por estas poderem ser bastante criativas, controlar apenas uma forma de comportamento, ao ter, por exemplo, uma política de controle de faltas, deixa a raiz do problema intacta. Para controlar eficazmente as consequências indesejáveis da desmotivação no trabalho, os empregadores devem atacar a fonte do problema, a insatisfação, em vez de tentar controlar as diferentes reações.

Assim, dadas às evidências, percebe-se que a motivação no trabalho pode afetar os resultados das empresas. O gesto mais importante que os gestores podem fazer para aumentar a motivação é focar os componentes intrínsecos do trabalho, tais como tornálo mais desafiador e interessante.

\section{Metodologia}

O estudo foi realizado por meio de métodos e técnicas a seguir descritos: o método 
utilizado foi o indutivo que, de acordo com Martins (2002, p. 28) "é um método lógico que pressupõe que existam verdades gerais já afirmadas e que sirvam de base (premissas) para se chegar através dele os conhecimentos novos", ou seja, que fornece diversas informações sobre a motivação.

O método de procedimento empregado foi o monográfico, no qual se realizou um estudo com os colaboradores da empresa pesquisada, e o estatístico, cujos dados foram tabulados e apresentados em percentuais, através de gráficos.

Foi utilizado um instrumento estruturado que é o questionário, com questões fechadas e abertas, considerando como universo 20 (vinte) colaboradores. Os questionários foram entregues no mês de março, contendo em anexo uma Carta de Apresentação com os dados sobre a pesquisa, bem como orientações sobre o preenchimento do questionário e o resguardo da identificação do pesquisado. Os questionários foram devolvidos no prazo estipulado.

Foi utilizada a pesquisa bibliográfica desenvolvida mediante material já elaborado, principalmente livros e artigos científicos. Utilizou-se também a pesquisa explicativa que segundo Gil (1999) visa observar, registrar, analisar e interpretar os fenômenos estudados, procurando identificar as causas. Também foi utilizada a pesquisa qualitativa, sendo uma pesquisa exploratória, que estimulou os entrevistados a pensarem livremente sobre o tema em questão. Os dados foram analisados e tabulados através da regra de três simples. Os resultados foram demonstrados por meio de tabelas e gráficos.

\section{Resultados e Discussão}

O Supermercado Triunfo é uma empresa familiar e foi inaugurado há23 anos. E ao longo desse período teve algumas alterações como a ampliação do espaço físico do estabelecimento, bem como, alteração na estrutura societária da empresa.

A empresa vende seus produtos para o município de Paranaíta e região. Todos os funcionários têm salários fixos de acordo com a formação e a função que exercem. A empresa oferece incentivo e gratificação para seus colaboradores.

O objetivo principal deste estudo foi identificar se a motivação é um fator relevante no desempenho dos colaboradores da empresa. O questionário foi aplicado a 
todos os funcionários da empresa, chegando aos seguintes resultados:

O perfil dos pesquisados é definido por60\% pertencentes ao sexo feminino, $30 \%$ tem até 20 anos de idade e $30 \%$ trabalham na empresa a menos de 1 ano.

No gráfico número $1,75 \%$ dos trabalhadores admitem que a motivação é um fator relevante para o desempenho na empresa, mas $25 \%$ dos entrevistados diferem dessa opinião.

Gráfico 1: A motivação é um fator relevante para o desempenho dos colaboradores.

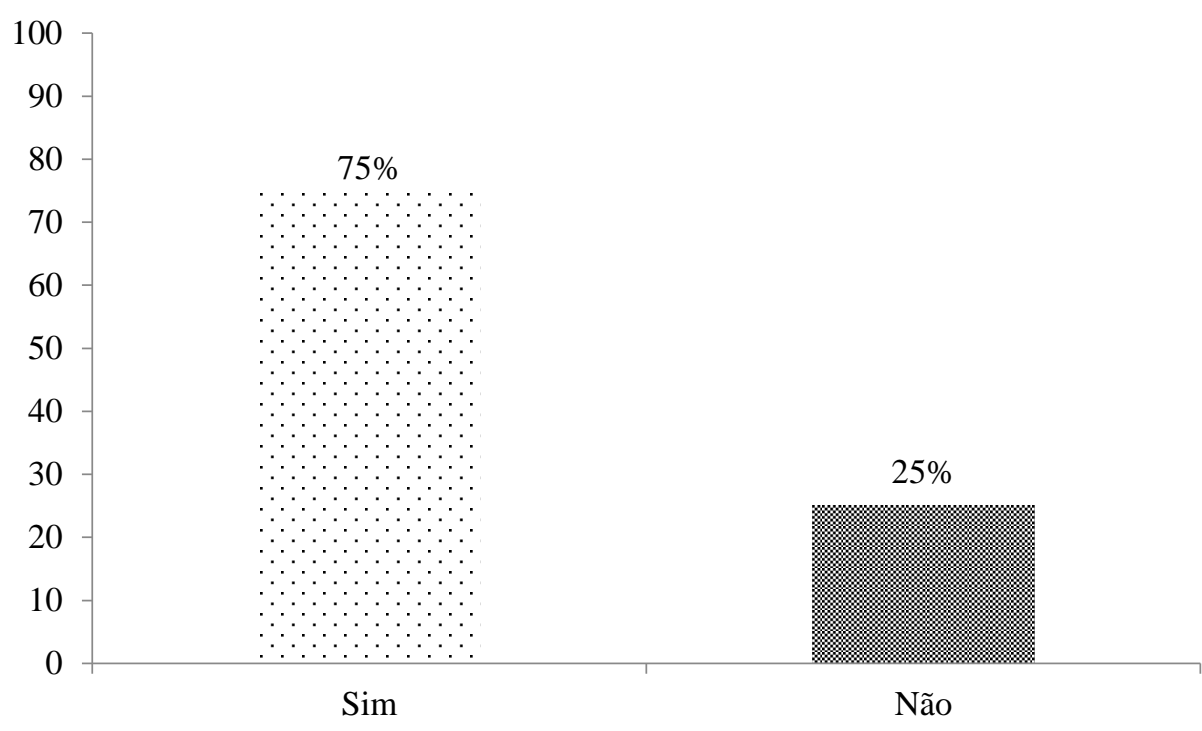

Fonte: Elaborado pelas Autoras baseando-se em Questionário da pesquisa.

Para Bergamini (2008), o indivíduo pode até estar capacitado ou habilitado para desenvolver certa atividade, mas se não for do interesse do mesmo, se não houver um gerador de ação instalado na sua personalidade, ou seja, se ele não estiver verdadeiramente motivado, ele não a desenvolverá com eficácia.

A verdadeira motivação representa, portanto, um desejo natural das pessoas que se engajam nas atividades desse trabalho por amor a ele mesmo, tendo em vista a satisfação que ele pode oferecer.

O gráfico número 2 demonstra que são quatro os fatores que mais motivam os trabalhadores, $40 \%$ responderam que é o salário, $30 \%$ a atividade que exercem, $20 \%$ ao bom relacionamento com o empregador e apenas $10 \%$ concordam que o bom 
relacionamento com os colegas de trabalho é que faz diferença.

Gráfico 2: Fator que mais o motiva em seu ambiente de trabalho.

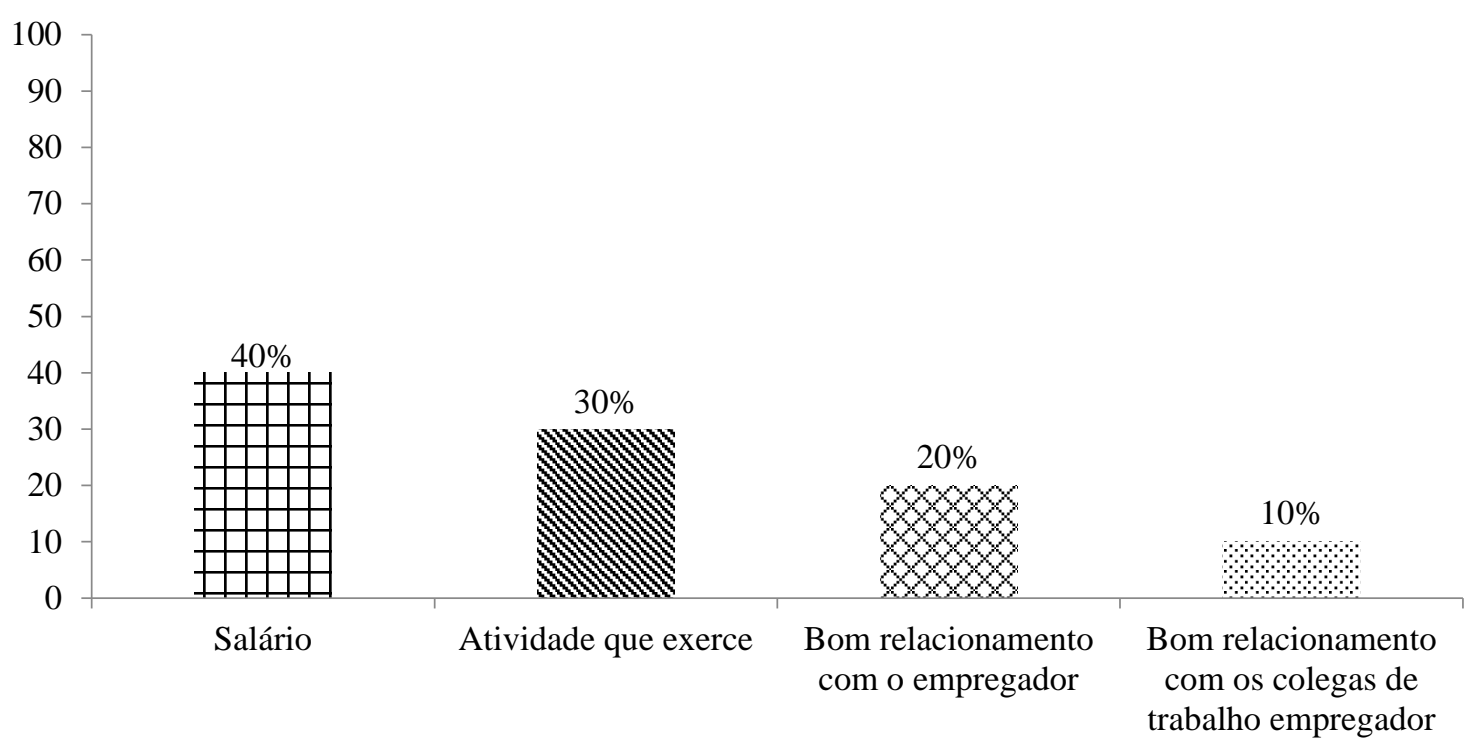

Fonte: Elaborado pelas Autoras baseando-se em Questionário da pesquisa.

Segundo Chiavenato (2000), a recompensa salarial não é mais o único fator decisivo na satisfação do indivíduo dentro das situações de trabalho, o indivíduo precisa também de recompensas sociais e simbólicas. Como o reconhecimento de suas habilidades profissionais, a afirmação de sua postura pessoal e organizacional e de sua importância para o bom desempenho da equipe da qual faz parte, é preciso que cada parte saiba exatamente o valor que tem para o todo.

Percebe-se que os indivíduos são distintos no que se refere às ações motivacionais . A motivação de um colaborador pode ser entendida como salários mais altos, outros como valorização profissional, outros ainda como promoções, ou seja, existem colaboradores com ideias, objetivos e preocupações diferentes.

O salário não é o fator que mais motiva os colaboradores no ambiente de trabalho, assim, essa hipótese foi refutada.

O gráfico 3 demonstra se o ambiente de trabalho interfere ou não no desempenho da equipe, obtendo que $85 \%$ dos pesquisados acreditam na interferência e $15 \%$ responderam que não há. 
Gráfico 3: O ambiente de trabalho interfere no desempenho da equipe.

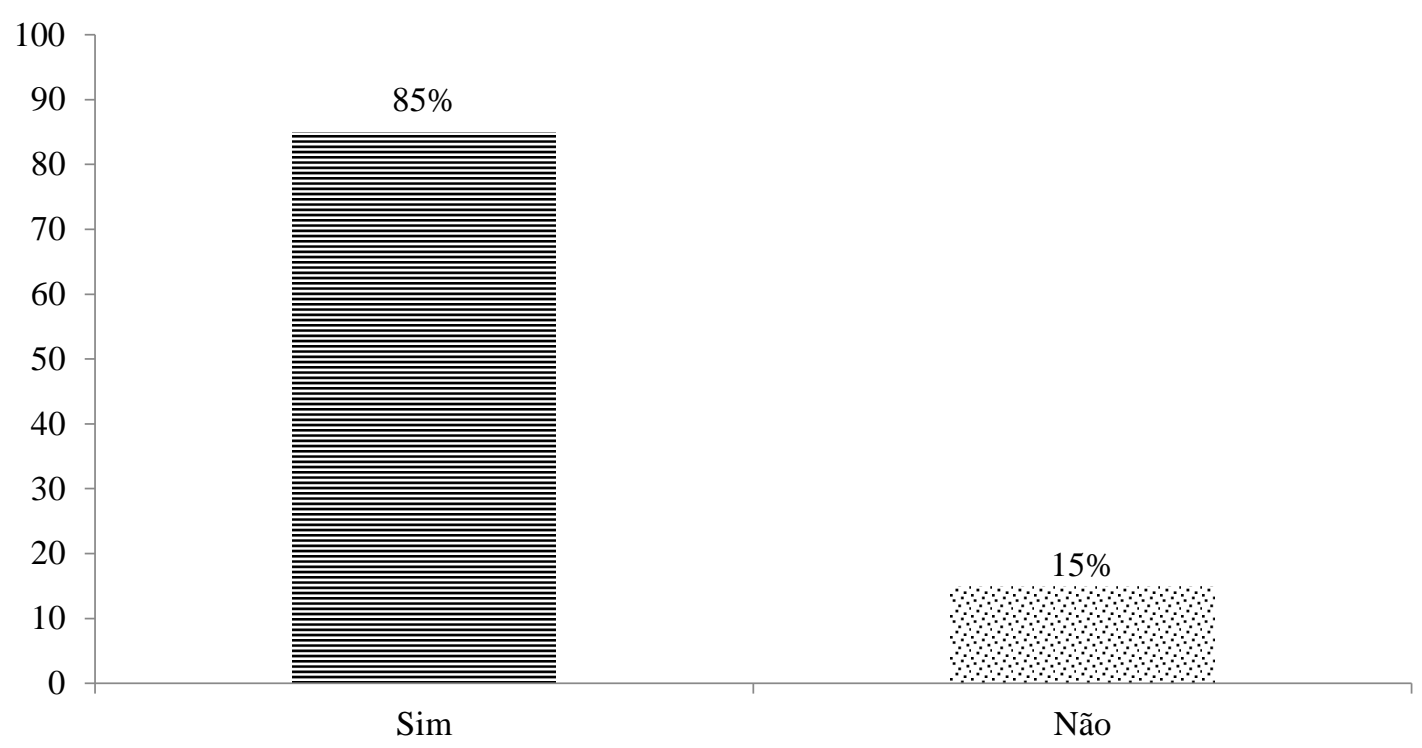

Fonte: Elaborado pelas Autoras baseando-se em Questionário - Anexo

Para Chiavenato (2003), os fatores como o relacionamento, clima organizacional, ambiente de trabalho se localizam no espaço que rodeia as pessoas e abrange as condições dentro das quais elas desempenham seu trabalho. Como essas condições são administrativas e decididas pela empresa, tais fatores estão fora do controle das pessoas. São fatores do contexto e se situam no ambiente externo que circunda o individuo.

No ambiente organizacional, é de fundamental importância que todos se respeitem que tenham um bom relacionamento fazendo com que o trabalho se torne mais agradável e que todos possam sentir-se motivados para desempenhar cada vez melhor suas tarefas.

Assim, pode-se perceber que para motivar o trabalhador é necessário investir nos ambientes, físico (ferramentas e instalações) e psicológico (relacionamentos), criando dessa forma um ambiente positivo para o desempenho da equipe e das necessidades dos trabalhadores.

Este resultado vem confirmar a hipótese levantada, que o ambiente de trabalho interfere no desempenho da equipe.

O gráfico número 4 constata que $90 \%$ concordam que existe um bom relacionamento entre o empregado e o empregador, já 10\% discordam dessa afirmação. 
Gráfico 4: Existe um bom relacionamento entre você e o empregador.

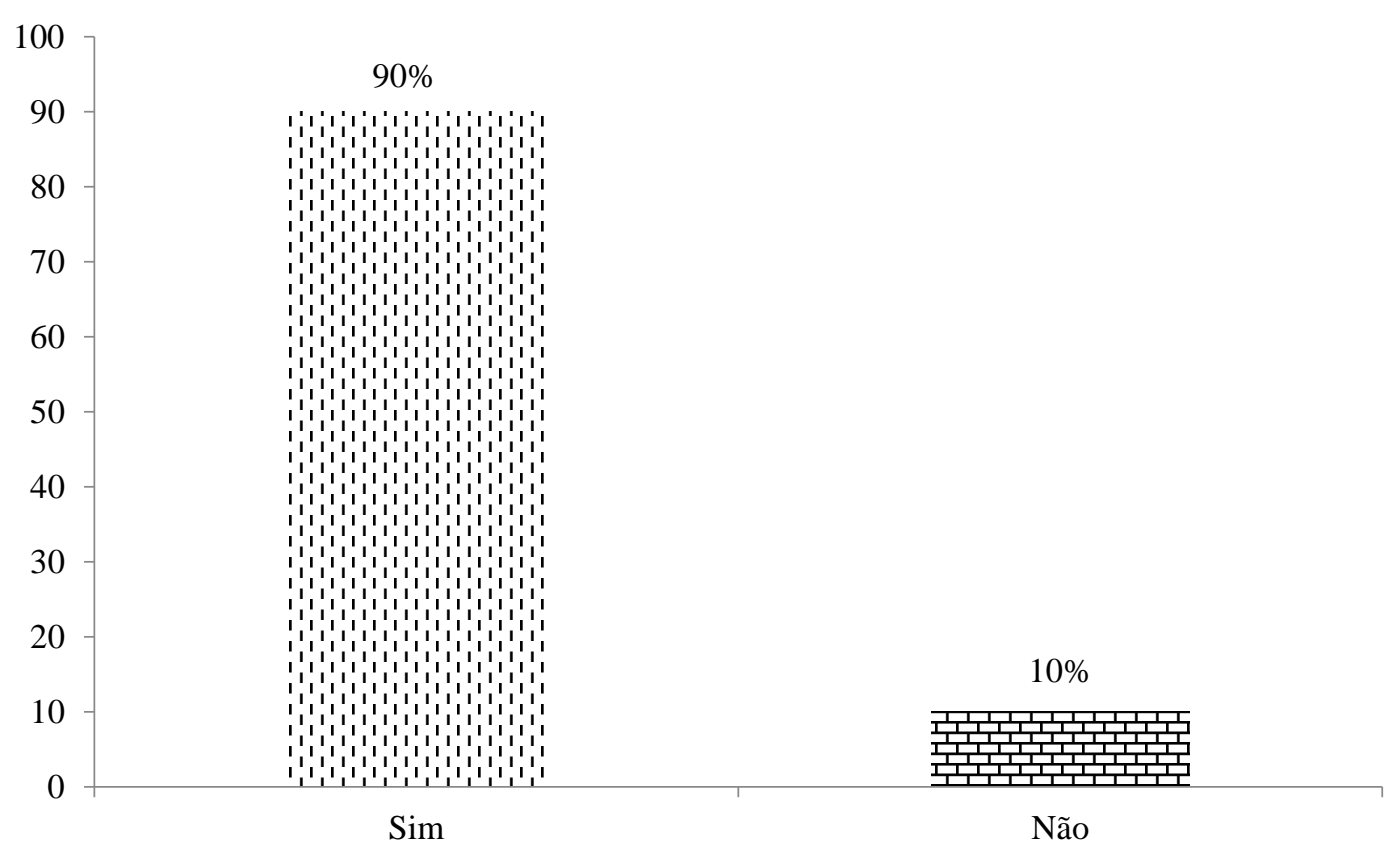

Fonte: Elaborado pelas Autoras baseando-se em Questionário - Anexo

De acordo com Chiavenato (1998) a vida das pessoas constitui uma infinidade de interações com outras pessoas e com organizações. O ser humano é eminentemente social e interativo. Não vive isoladamente, mas em constante convívio e relacionamento com seus semelhantes.

As relações humanas estão presentes no ambiente organizacional, daí a importância do investimento cada vez maior por parte dos gestores na busca constante para maior envolvimento e comprometimento das pessoas com a organização. É de suma importância que as pessoas se mantenham motivadas.

Dessa forma, o trabalhador precisa interagir bem com as pessoas dento empresa, seja com seus superiores ou em relação aos demais colegas de trabalho, ou ainda em relação ao mercado onde se encontra atuando.

Um funcionário que convive com todos em harmonia e respeito, pode executar melhor suas tarefas. Assim, confirma-se a hipótese levantada que existe um bom relacionamento entre colaborador e seu empregador. 
O gráfico número 5 expõe que $80 \%$ dos pesquisados admitem que a falta de motivação pode interferir no bom desempenho dos colaboradores e apenas $20 \%$ não concordam que essa interferência possa ocorrer.

Gráfico 5: A falta de motivação pode interferir no bom desempenho dos colaboradores.

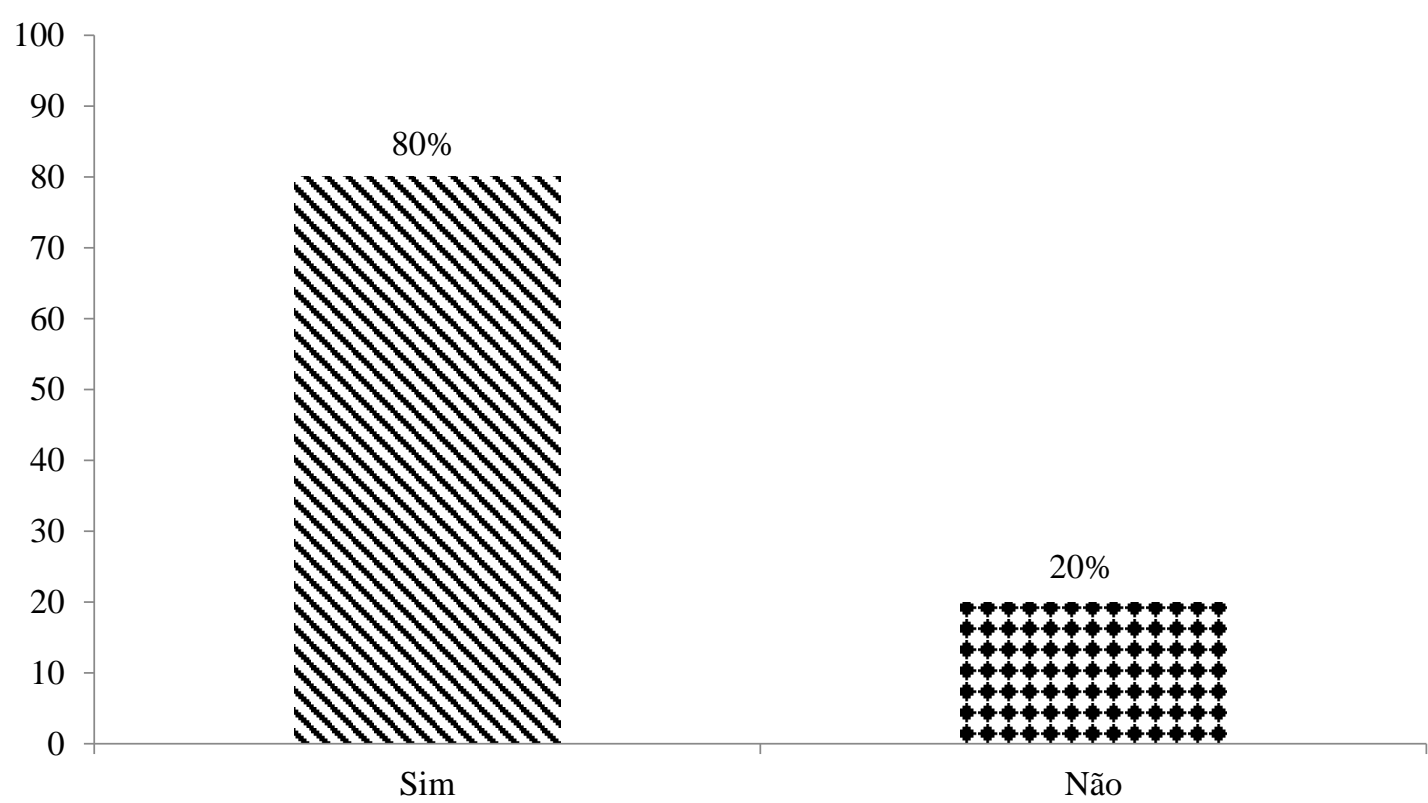

Fonte: Elaborado pelas Autoras baseando-se em Questionário - Anexo

Alguns psicólogos afirmam segundo Chiavenato (2003) que motivação é o desejo consciente de se obter algo, sendo, assim, uma determinante da forma como o indivíduo se comporta.

É através da motivação do funcionário que a empresa obterá maior capacidade de produção, ou seja, um colaborador motivado terá um melhor desempenho em suas tarefas.

Segundo Bergamini (1997) para a empresa manter um quadro de colaboradores desenvolvendo suas funções satisfatoriamente é imprescindível à motivação, tanto pessoal, como emocional e profissional. A característica atual do mercado de trabalho não é mais estática e rotineira e isso exige da equipe colaboradora uma carga excedente de desempenho, tanto no que se refere ao volume de trabalho quanto à variedade de 
tarefas executadas. E esse fator acaba desgastando a relação empresa/colaborador.

Isto evidencia a necessidade crescente da constante motivação dos funcionários, que precisam ser visualizados sob uma nova perspectiva, devem ser motivados a assumirem um papel de colaborador, ser respeitado e remunerado como um colaborador e não apenas como um funcionário a mais.

Dessa forma, confirma-se a hipótese levantada de que a falta de motivação pode interferir no bom desempenho dos colaboradores.

O gráfico número 6 demonstra que $95 \%$ acreditam que o clima organizacional melhora o desempenho da equipe e apenas 5\% responderam que não consideram esse fator como significante para o desempenho dos trabalhadores.

Gráfico 6: O clima organizacional melhora o desempenho da equipe.

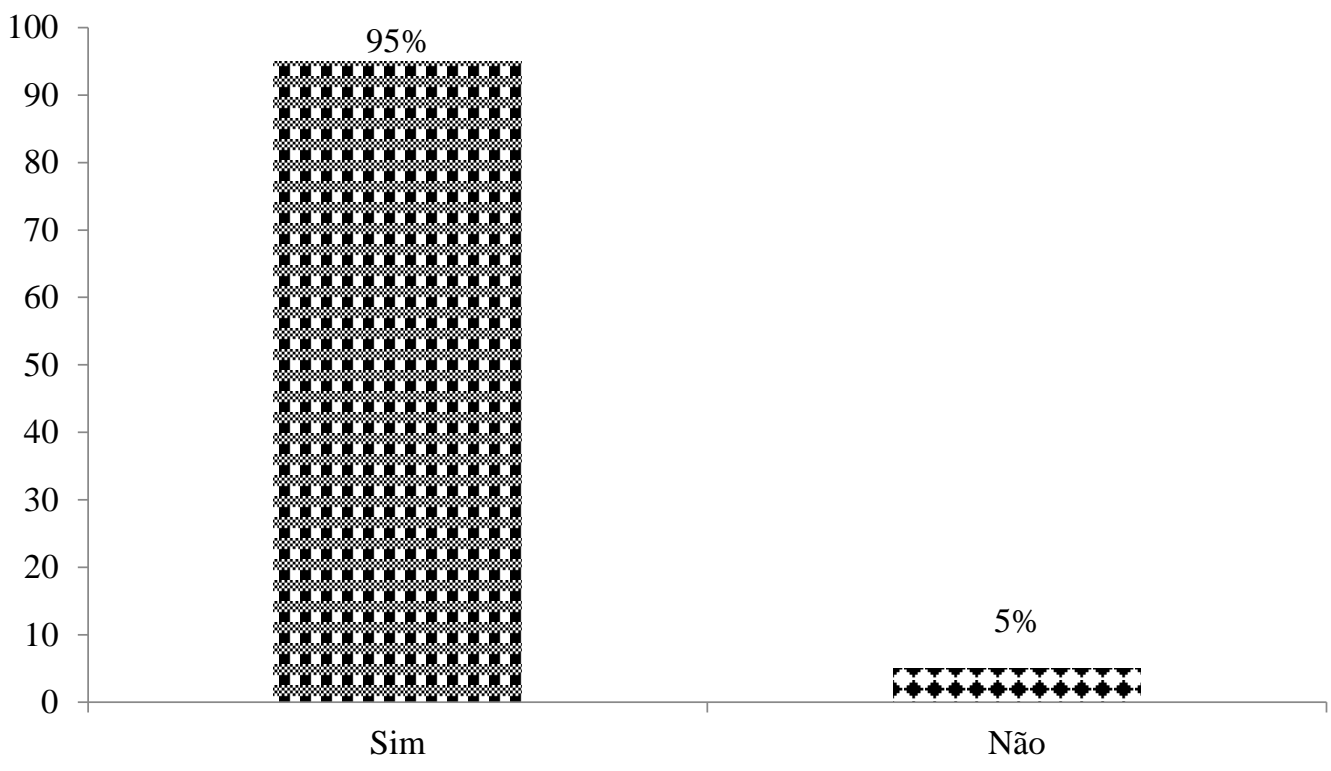

Fonte: Elaborado pelas Autoras baseando-se em Questionário - Anexo

Para Chiavenato (2003), o clima organizacional está intimamente relacionado com o grau de motivação de seus participantes. Quando há elevada motivação entre os membros o clima motivacional se eleva e se traduz em relações de satisfação, animação, interesse, colaboração; todavia, quando há baixa motivação entre os membros seja por frustração ou barreiras à satisfação das necessidades o clima organizacional tende a 
abaixar caracterizando-se por estados de depressão, desinteresse, apatia, insatisfação, podendo, em casos extremos chegar à agressividade, tumulto, inconformidade, típicos de situações em que os membros se defrontam abertamente com a organização.

O clima organizacional influencia a motivação, o desempenho humano e a satisfação no trabalho. Pode-se dizer que o clima organizacional influencia e é influenciado pelo estado motivacional das pessoas, portanto é um reflexo direto dos níveis motivacionais.

O gráfico número 7 mostra que $75 \%$ dos trabalhadores acreditam no reconhecimento do seu trabalho pela empresa e $25 \%$ responderam que não há essa valorização.

Gráfico 7: O colaborador é reconhecido pela empresa.

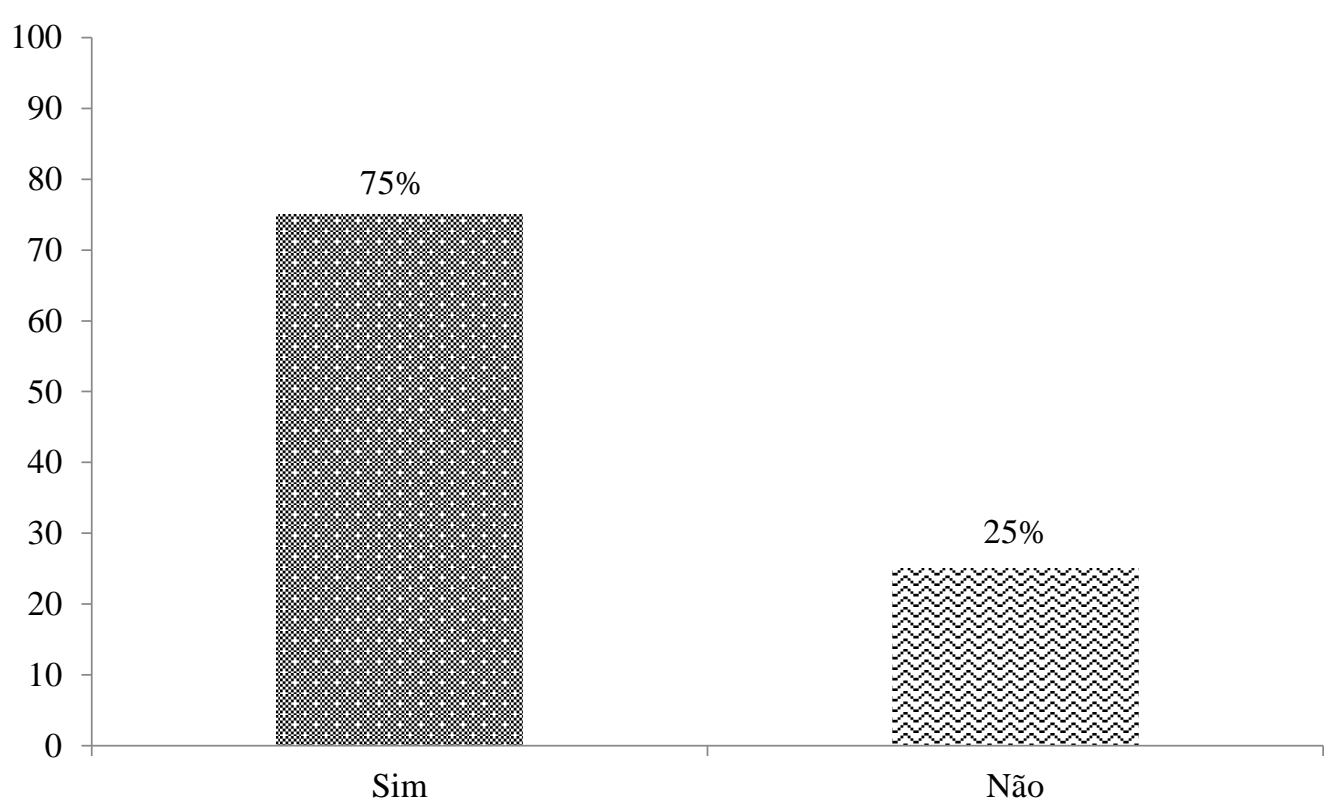

Fonte: Elaborado pelas Autoras baseando-se em Questionário - Anexo

Segundo Morin (2001, p.18), “para que um trabalho tenha sentido, é importante que quem realize saiba para onde ele conduz; em outras palavras, é essencial que os objetivos sejam claros e valorizados e que os resultados tenham valor aos olhos de quem realiza".

As pessoas efetivamente se envolvem, 'vestem' a camisa, quando se emocionam 
pelo que fazem, percebem a possibilidade de criar, inovar, fazer diferente. A satisfação no trabalho é dinâmica, uma vez que pode deteriorar-se tão rapidamente quanto desenvolver-se.

Portanto é interessante fomentar a satisfação dos funcionários quando tem seu trabalho reconhecido, visto que este reconhecimento promove maior envolvimento no trabalho, o que leva os trabalhadores a tornarem-se dedicados e produtivos.

Nota-se que os fatores motivacionais, como reconhecimento, relações interpessoais, clima organizacional impulsionam os colaboradores ao desenvolvimento de suas atividades com mais ânimo, comprometimento e eficiência, gerando assim acréscimo de produtividade e melhor desempenho.

\section{Considerações Finais}

O estudo abordou o tema fatores motivacionais que influenciam no desempenho do colaboradoralcançando o objetivo proposto de identificar se a motivação é um fator relevante no desempenho dos colaboradores da empresa.

Ao término da pesquisa percebeu-se que a falta de motivação pode interferir no bom desempenho dos colaboradores dentro da empresa e que existe uma relação agradável entre trabalhador e superior. Verificou-se ainda que o salário não é o fator que motiva os colaboradores no desempenho de seu trabalho e que o ambiente de trabalho interfere no desempenho da equipe.

Percebe-se desta forma, o ser humano tem muitas capacidades e pode exercer diversas funções com maior ou menor habilidade. No entanto, para que o máximo de eficiência seja alcançada nas organizações empresariais é necessário que estejam todos motivados.

De acordo comChiavenato (2005), as pessoas precisam ser enxergadas como parceiras da empresa e isso quer dizer que são contribuintes das suas habilidades, competências e do seu modo de pensar. A instituição é considerada um ambiente ideal para a troca de ideias e eficiência.

Quanto mais houver união entre a equipe de colaboradores mais estarão ativos em 
busca de melhorias. Entretanto, quando não há essa integração, o individualismo se destaca (O’DONNELL, 2006).

Ainda, o encerramento deste trabalho foi de grande importância tanto para a empresa que se prontificou a participar como para a sociedade, além da contribuição que trouxe para o meio acadêmico e demais profissional da área. Sãofundamentais novos estudos sobre a temática, pois há necessidade de pesquisa na área empresarial e no capital humano da empresa, o funcionário, abordando eixos como tendências do mercado de trabalho e o futuro dos profissionais aliados à tecnologia.

Finalizando, espera-se como pesquisador que as informações coletadas contribuam para que as empresas invistam em seus funcionários, através de cursos ou gratificações, que os valorizem pela sua contribuição e assim cresçam juntos, haja visto que o contrário dessas atitudes tem consequências negativas para a empresa como o insucesso na atuação profissional dos trabalhadores.

\section{Referências}

BERGAMINI, C. W. Motivação nas Organizações. São Paulo: Atlas, 1997.

CASTRO, C. M. A prática da Pesquisa. São Paulo: Pearson Prentice Hall, 2006.

CHIAVENATO, I. RecursosHumanos. São Paulo: Atlas, 2002.

Gestão de pessoas: o novo papel dos recursos humanos nas organizações. Rio de Janeiro: Campus, 1999.

Introdução à teoria geral da administração. Rio de Janeiro: Campus, 2003.

Gerenciando com as Pessoas: transformando o executivo em um excelente gestor de pessoas. Rio de Janeiro: Elsevier, 2005.

FIORELLI, J. O. Psicologia para administradores. São Paulo: Atlas, 2004.

KANNANE, R. Comportamentos humanos nas organizações. São Paulo: Atlas, 1995.

KOLB, D. A. (org). Psicologia organizacional. São Paulo: Atlas, 1996.

O’ DONNELL, K. Valores Humanos no Trabalho. São Paulo: Gente, 2006. 
ROBBINS, S. P. Comportamento organizacional. São Paulo: Pearson Prentice Hall, 2010.

VERGARA, S. C. Projetos e relatórios de pesquisa em administração. São Paulo: Atlas, 2007.

VIANNA, M. A. Motivação, Liderança e Lucro. São Paulo: Gente, 1999.

\section{Como citar este artigo (Formato ABNT):}

MARTINS, Cimara de Souza; RIBEIRO, Mariana Emídio O.; ANTONIOLLI, Bianca I.; SILVA, José Marcos S da. Fatores Motivacionais que influenciam no desempenho dos colaboradores no Ambiente de Trabalho. Id on Line Revista ultidisciplinar e de Psicologia, 2017, vol.12, n.39, p.262-281. ISSN: 1981-1179.

Recebido: 28.11.2017

Aceito: 05.12.2017

\section{QUESTIONÁRIO DA PESQUISA}

1 Qual é o seu sexo?

( ) feminino ( ) masculino

2 Qual é a sua idade?
( ) até 20
( ) de 21 a 30
( ) de 31 a 40
( ) acima de 40

3 Há quanto tempo você trabalha na empresa?
( ) até 1 ano
( ) de 1 a 5 anos
( ) de 5 a 10 anos
( ) acima de 10 anos

$4 \mathrm{Na}$ sua opinião, a motivação é um fator relevante para o desempenho dos colaboradores?
( ) $\operatorname{sim}$
( ) não

5 Qual é o fator que motiva no ambiente de trabalho?(marque apenas 1 opção)

( ) salário

( ) atividade que você exerce

( ) bom relacionamento com os colegas de trabalho

( ) bom relacionamento com o empregador 
$6 \mathrm{O}$ ambiente de trabalho interfere no desempenho da equipe?

( ) $\operatorname{sim} \quad($ ) não

7 Existe um bom relacionamento entre você e o empregador?

( ) $\operatorname{sim} \quad($ ) não

8 A falta de motivação pode interferir no bom desempenho dos colaboradores?

( ) $\operatorname{sim}$ ( ) não

9 Os colaboradores da empresa são motivados frequentemente por seus superiores?

( ) $\operatorname{sim} \quad$ ( ) não

10 Para você, o clima organizacional melhora o desempenho da equipe?

( ) $\operatorname{sim} \quad($ ) não

11 A motivação influencia no desempenho dos funcionários dentro do ambiente de trabalho?

( ) $\operatorname{sim}$ ( ) não

12 Sente que o colaborador é reconhecido pela empresa?

( ) $\operatorname{sim}$ ( ) não

13 Sente-se motivado em executar atividades no setor que trabalha?

( ) $\operatorname{sim}$ ( ) não

14 Considera a sua relação e seu lider agradável?

( ) $\operatorname{sim} \quad($ ) não

15 A remuneração oferecida está de acordo com as funções desempenhadas?

( ) $\operatorname{sim}$ ( ) não

16 A empresa proporciona um ambiente agradável para a realização das tarefas cotidianas?
( ) $\operatorname{sim}$
( ) não

17 Quais sugestões daria para melhorar a motivação dos colaboradores na empresa? 